\section{Nuevo virus de importancia en el tamizaje de donantes de sangre}

Desde 1995, año en que se identificó y notificó la presencia de ácido desoxirribonucleico $(\mathrm{ADN})$ de un herpesvirus gamma en individuos infectados por VIH con sarcoma de Kaposi (SK), se dispone de datos suficientes para postular como agente causal de ese tumor a un nuevo virus, denominado virus del herpes humano 8 (VHH-8). Más aún, los estudios serológicos, que se iniciaron en 1996, apoyan la asociación entre el VHH-8 y el SK, si bien los anticuerpos específicos contra el virus también se detectan en individuos sanos (en donantes de sangre, su prevalencia es de $2 \%$ en Gran Bretaña y de 0 a $20 \%$ en los Estados Unidos de América).

En la comunicación preliminar que suscita el presente comentario, Blackbourn, et al. notifican la presencia de anticuerpos y de virus infectivo en un individuo sano. Estos investigadores obtuvieron linfocitos CD19+ de la sangre periférica de 11 donantes que acudieron a un banco de sangre en los Estados Unidos. Los linfocitos fueron cultivados y sometidos a análisis por el método de reacción en cadena de la polimerasa (PCR) para la detección de secuencias de ADN de VHH-8. En el único caso con resultados positivos se confirmó la infectividad del virus aislado mediante la detección de ácido ribonucleico viral en células inoculadas y posteriormente cultivadas por un período de 3 días.

El donante infectado fue excluido permanentemente de la lista de donantes en espera de las recomendaciones de la Administración Federal de Medicamentos acerca de los donantes positivos a VHH-8. Con respecto al caso aquí descrito, las autoridades del banco de sangre confirmaron la eliminación de la sangre contaminada y la ausencia de antecedentes de donaciones previas. Esta es la primera indicación de que el VHH-8 es un virus infectivo que se puede aislar de la sangre de individuos sanos. La posibilidad de transmisión a partir de transfusiones de sangre y hemoderivados debe explorarse mediante estudios adicionales. (Blackbourn DJ, Ambroziak J, Lennette E, Adams M, Ramachandran B, Levy JA. Infectious human herpesvirus 8 in a healthy North American blood donor. Lancet 1997;349:609-611).
Valor de la aspirina o heparina en el tratamiento
de los accidentes cerebrovasculares

Cada año, varios millones de personas en el mundo son tratadas por accidentes cerebrovasculares $(\mathrm{ACV})$ isquémicos agudos. Si algún tratamiento pudiera prevenir la muerte o la dependencia de por lo menos 10 de cada 1000 pacientes, ya estaría ampliamente justificado. Si bien los tratamientos más invocados son la heparina y la aspirina, con respecto a la primera los resultados de estudios sobre su uso han dado lugar a interpretaciones conflictivas debido, en parte, al tamaño reducido de las muestras estudiadas. De ahí que se esperaran con comprensible interés las conclusiones a que habrían de llegar los responsables del mayor ensayo jamás realizado para evaluar el tratamiento agudo de los $\mathrm{ACV}$ isquémicos, cuyos resultados se dieron a conocer en mayo de este año.

Como la mayoría de los ACV se deben a oclusión aguda de una arteria cerebral, está ampliamente difundido el uso de anticoagulantes para facilitar la lisis del coágulo, inhibir la propagación del trombo en las arterias cerebrales y prevenir la reembolización o la trombosis por inmovilidad de miembros inferiores. Sin embargo, hasta ahora ha habido pocas pruebas de los riesgos y beneficios del tratamiento con heparina, aspirina, o ambas sustancias. Con el fin de establecer la eficacia y la inocuidad de estos tratamientos, se llevó a cabo un gran ensayo internacional aleatorio y abierto en pacientes con trastornos cerebrovasculares (International Stroke Trial, IST), destinado a evaluar el efecto de un tratamiento antitrombótico de iniciación temprana y de 14 días de duración. El ensayo incluyó a 19435 pacientes con sospecha de ACV isquémico agudo que provenían de 467 hospitales en 36 países. Se conformaron cuatro grupos de igual tamaño, según el régimen terapéutico adoptado: 1) aspirina, 300 mg diarios; 2) heparina subcutánea, en dos dosis diarias de 5000 ó 12500 UI; 3) aspirina más heparina y 4) ni heparina, ni aspirina. Como parámetros para evaluar la evolución del paciente se tomaron la presencia o ausencia de muerte en los primeros 14 días y la dependencia a los 6 meses del ACV.

Se desprende del análisis estadístico de los resultados que el tratamiento con heparina no redundó en ningún beneficio clínico a los 6 meses del ACV. Si se insistiera en emplearlo para la profi- 
laxis de trombosis de venas profundas, no deberían administrarse más de dos dosis diarias de 5000 UI subcutáneas. El IST reveló una pequeña pero estimable mejoría al cabo de 6 meses en pacientes tratados con aspirina. Si los datos de ese estudio se suman a los de un ensayo chino de similar magnitud (Chinese Acute Stroke Trial), se puede concluir que la aspirina previene la muerte o la recurrencia de ACV en alrededor de $1 \%$ de los pacientes. Ambos estudios sugieren que el tratamiento con aspirina debe iniciarse lo más temprano posible después de un ACV isquémico. Estos resultados coinciden con los de estudios anteriores, según los cuales la administración de aspirina a dosis bajas confiere protección a largo plazo.

La combinación de una dosis pequeña de heparina subcutánea y aspirina pareció brindar mejores resultados a corto plazo que la aspirina sola, aunque esta observación se basa en una muestra de pacientes muy reducida $(6000)$. Es preciso tener una muestra mínima de 20000 pacientes para poder confirmar el beneficio de añadir una pequeña dosis de heparina al tratamiento con aspirina.

Sobre la base de la experiencia aportada por más de 40000 pacientes elegidos aleatoriamente que se beneficiaron de un tratamiento a base de aspirina sola, se concluye que el tratamiento inmediato con aspirina (a una dosis inicial de $300 \mathrm{mg}$ y una dosis de mantenimiento más baja) debe contemplarse, a no ser que existan contraindicaciones, en todo paciente con ACV isquémico agudo en que se haya descartado la presencia de hemorragia cerebral. (International Stroke Trial Collaborative Group. The International Stroke Trial (IST): a randomized trial of aspirin, subcutaneous heparin, both, or neither among 19435 patients with acute ischaemic stroke. Lancet 1997;349:1569-1577).

\section{La integración de la genética a la oncología}

En 1994 se presenció una incorporación de la genética al campo de la oncología, en virtud del descubrimiento de los genes responsables de la susceptibilidad a determinados tipos de cáncer. Inicialmente se estableció que mujeres con antecedentes familiares marcados de cáncer de ovario, mama, o ambos, y al mismo tiempo portadoras de una mutación en la línea germinal del gen $B R C A 1$, presentaban riesgos de 85 y $60 \%$ de desarrollar cáncer de mama y ovario, respectivamente, durante su ciclo vital. Con la posterior identificación del gen $B R C A 2$ llegó a suponerse que la mayoría de los cánceres de mama de tipo familiar estaban determinados por esos dos genes. En consecuencia, se justificó la ulterior búsqueda de análisis genéticos que permitieran hacer un diagnóstico precoz, así como la realización de investigaciones que, en un contexto muy competitivo, se encaminaban al descubrimiento de nuevos genes y al desarrollo de métodos de tamizaje para su detección.

Tres años más tarde se hace oportuno revisar lo acontecido hasta el momento. En cuatro artículos publicados en la New England Journal of Medicine se llama la atención a las limitaciones del análisis genético, si se pretende que sus resultados sean categóricamente proféticos. Según manifiesta B. Healy en un editorial que apareció en el mismo número de la revista, el problema no radica en la validez de la información, sino en su aplicación inadecuada.

Couch, et al., tras un estudio emprendido con el propósito de desarrollar un modelo predictivo para mujeres con antecedentes familiares de cáncer de mama y mutación del gen BRCA1, concluyen que el tamizaje para detectar esta mutación representa un gasto sin mayor provecho. Dado que la mutación se encontró en 7\% de las mujeres estudiadas, se espera un resultado negativo en cerca de 93\% de los casos, situación que puede llevar a una falsa sensación de seguridad y quizá a un descuido de las prácticas preventivas. Por otra parte, la sobreestimación del riesgo representado por estos genes puede conducir a la reiteración de pruebas sin mayor significado e incluso a intervenciones mutilantes y traumatizantes.

En los dos genes $B R C A$ se han descrito más de 200 mutaciones, asociadas en su mayor parte con la capacidad de un gen supresor putativo para bloquear el desarrollo de un cáncer. Sin embargo, diferentes mutaciones pueden asociarse con diferentes riesgos de sufrir cáncer de mama, ovario u otros órganos y también con distintas probabilidades en cuanto a tipo histológico de tumor y a índice de progresión. A ese respecto, Krainer, et al. han comprobado que las mutaciones del gen $B R C A 2$ contribuyen a un menor número de cánceres que las del gen BRCA1.

Incluso una misma mutación puede comportarse de diferente forma en distintas mujeres. Struewing, et al. investigaron el riesgo de cáncer en un grupo numeroso de judías ashkenazim que, en virtud de su extracción étnica, presentaban una de las tres mutaciones específicas de los genes $B R C A$. La contribución de esas mutaciones al cáncer fue muy escasa ( $50 \%$ al de mama y $16 \%$ al de ovario), si se tiene en cuenta que estudios anteriores en mujeres con antecedentes familiares de esos cánceres habían arrojado valores de 87 y $64 \%$, respectivamente. Todos estos datos resaltan la influencia de factores modificadores (genéticos, hormonales, dietéticos o ambientales) en el riesgo de que una mutación particular de un gen $B R C A$ llegue a causar cáncer. A ello se suma el descubrimiento de nuevos genes que predisponen al 
cáncer por diferentes mecanismos, entre ellos la disminución del metabolismo estrogénico.

Para evaluar si es o no justificable la mastectomía u ooforectomía profiláctica en portadoras de mutaciones de lo genes $B R C A 1$ y $B R C A 2$, Schrag, et al. diseñaron un modelo teórico para predecir la esperanza de vida promedio de esas mujeres, estimándola en 3 a 5 años de vida adicional después de la mastectomía y en 4 a 20 meses adicionales después de la ooforectomía. Esos valores abogan por un manejo conservador de las portadoras de la mutación, ya que no difieren mayormente de los correspondientes a mujeres que no son portadoras.

Según Healy, todavía no se dispone de datos suficientes para incorporar a la práctica clínica diaria la prueba detectora de mutaciones de los genes $B R C A$, puesto que sus resultados siguen siendo discutibles. Tanto los médicos como sus pacientes deberían ser conscientes de las consecuencias de sobreestimar el valor de esa información y de adoptar procedimientos profilácticos cuyos beneficios no se hayan confirmado. (Healy B. BRCA genes: bookmaking, fortunetelling, and medical care. $N$ Engl J Med 1997;336:1448-1449).

\section{Infección por VIH y otras enfermedades de transmisión sexual en mujeres de México, DF}

Desde 1986, la incidencia de sida en la mujer se ha incrementado en México de forma acelerada. La infección, asociada inicialmente a transfusión sanguínea, ha estado predominantemente vinculada a transmisión sexual desde 1992. Para diciembre de 1994 se habían notificado 2833 casos de sida en mujeres, aunque se estimaba que el número real, teniendo en cuenta el subregistro y la notificación retrasada, debía ser mayor.

Ante la escasez de estudios en la población femenina en riesgo de contraer sida o enfermedades de transmisión sexual (ETS) y dada la necesidad de contar con programas dirigidos hacia esa población, Hernández-Girón, et al. analizaron las seroprevalencias de ciertas ETS y de sus principales factores de riesgo en un grupo de mujeres que durante 1992 se hicieron la prueba para la detección de virus de la inmunodeficiencia humana (VIH) en una clínica del Consejo Nacional de Prevención y Control del Sida de México, DF. Previo consentimiento informado, 454 mujeres respondieron a un cuestionario autoaplicado y estructurado en cuatro secciones (características sociodemográficas, antecedentes de ETS, antecedentes de transfusión sanguínea y comportamiento sexual riesgoso). En cada muestra de suero se investigó la presencia de anticuerpos contra Treponema pallidum, virus del herpes simple tipo 2, virus de la hepatitis B y VIH.
Entre los resultados del estudio destaca la prevalencia relativamente alta de $\mathrm{VIH}(4 \%)$, ya que otros autores habían estimado en $1 \%$ la frecuencia de infección en trabajadoras sexuales. Se encontró, además, que la baja escolaridad, el antecedente de transfusión sanguínea y el tener una pareja seropositiva eran factores predictivos de infección.

Desde que en 1986 se estableció en México la detección obligatoria de anticuerpos contra VIH en donantes de sangre, la frecuencia de casos de sida por transfusión sanguínea ha disminuido notablemente: de 68\% (147/215) en 1989 a 31\% (92/294) en 1994. No obstante, en el presente estudio se siguió encontrando una asociación significativa entre la infección por VIH y el antecedente de transfusión.

La seroprevalencia del agente causal de la sífilis $(4,6 \%)$ fue mayor que la notificada en otros estudios en mujeres representativas de la población en general (de 0,5 a $2,5 \%$ ), pero menor que la detectada en prostitutas $(8,2 \%)$. En cuanto a los otros marcadores serológicos, la seroprevalencia del virus del herpes simple tipo $2(29 \%)$ coincidió con la notificada previamente para la población femenina en general, y la del virus de la hepatitis B $(3,5 \%)$ fue menor que la observada en mujeres adolescentes (5,9\%).

En la discusión, los autores señalan las limitaciones del estudio, es decir, sus sesgos de autoselección (muestra representada por mujeres que espontáneamente solicitaron la prueba de VIH) y de información (validez no confirmada de las respuestas a preguntas sobre el número de parejas sexuales). Se sabe, sin embargo, que la positividad a VIH no influyó en la veracidad de las respuestas, ya que los resultados de la prueba se desconocían antes de llenar el cuestionario. En general, del trabajo se desprende la necesidad de reforzar el control en los bancos de sangre y otras instituciones, de ofrecer orientación sobre la aplicación de medidas preventivas y de difundir información sobre el riesgo de infección por VIH, ya que los resultados sugieren que este riesgo está determinado en gran medida por el comportamiento sexual de la pareja masculina. (Hernández-Girón C, Uribe-Salas F, CondeGonzález C, Cruz-Valdez A, Juárez-Figueroa L, Uribe-Zúñiga $P$, et al. Seroprevalencias a diversos virus y características sociodemográficas en mujeres que buscan detectarse VIH. Rev Invest Clin 1997; 49:5-13).

\section{Reforma psiquiátrica y salud mental en São Paulo}

Desde comienzos de la década de 1980, en el Brasil se han generado varios estudios tendientes a confirmar la poca efectividad de los hospitales psiquiátricos, el escaso beneficio de las hopitalizaciones, 
la propensión a la cronicidad de los síntomas y la frecuente violación de los derechos humanos de los internados. Se aprecia, por lo tanto, la necesidad de disponer de nuevos modelos alternativos a fin de gradualmente reemplazar la hospitalización por un conjunto de servicios ambulatorios para la atención primaria y secundaria de la salud mental. Ese cambio de enfoque en la atención psiquiátrica exige la disponibilidad de indicadores para evaluar su proyección, como podría ser una menor incidencia de ingresos. Para Lancman, es importante evaluar este índice en función de la existencia de hospitales psiquiátricos en una ciudad dada, ya que su presencia podría propiciar cierta convivencia entre los habitantes y el hospital y con ello una tendencia por parte de la población a "psiquiatrizar" sus problemas sociales cotidianos.

Para el estudio se seleccionaron cuatro ciudades, dos en el Estado de São Paulo (São Carlos y Araquara) y dos en la periferia de la capital (Ferraz de Vasconcelos y Franco de Rocha). Se recogieron datos sobre todos los pacientes que recibieron atención psiquiátrica en octubre y noviembre de 1990 y se trazó el perfil de la demanda de servicios psiquiátricos en los municipios, estableciéndose comparaciones entre los diferentes servicios y regiones.

En todos los municipios estudiados se constató un predominio acentuado de alcoholismo entre los hombres y de neurosis entre las mujeres. Se observaron, además, una mayor concentración de mujeres en todos los grupos de edad y un predominio de adultos jóvenes, así como pocos egresos, estancias demasiado largas en los servicios y un gran número de ingresos y reingresos. Aunque no llegó a confirmarse plenamente la hipótesis de que la presencia de un hospital psiquiátrico genera una mayor demanda de servicios de salud mental, se encontró una asociación directa entre la existencia de esos hospitales y un aumento del número de ingresos y consultas.

No es fácil, como destaca el artículo, transponer los indicadores epidemiológicos a las enfermedades mentales, ya que los parámetros comúnmente utilizados en la medicina asistencial no se adaptan, en muchas ocasiones, a la realidad de los servicios de salud mental. Los diagnósticos psiquiátricos son poco confiables, no solo por la falta de un esquema teórico de comprobación universal, sino también por la forma rápida y superficial con que muchas veces se establecen. De ahí que determinar la prevalencia de las afecciones mentales sea una tarea compleja pero necesaria para poder separar la influencia de los problemas personales de la de los entornos críticos y liberar gradualmente a los pacientes de los servicios de salud mental. (Lancman S. Instituições psiquiátricas e comunidades: um estudo de demanda em saúde mental no Estado de São Paulo, Brasil. Cad Saude Publica, Rio de Janeiro 1997;13:93-102).

\section{Hacia una definición del autismo}

En un intento por dejar de lado los prejuicios frecuentemente asociados con el autismo, I. Rapin efectúa una amplia revisión del tema partiendo de la base de que la afección pertenece a un grupo de alteraciones del desarrollo de la función cerebral. El autismo suele diagnosticarse entre los 18 y 30 meses de edad en niños con retraso o ausencia del habla y alteraciones de la sociabilidad. Los signos de autismo, observados con mayor frecuencia en varones, persisten en la adultez y pueden variar desde un lenguaje limitado e inaptitud para la vida diaria, hasta dificultad para seguir instrucciones o lograr algún grado de independencia. Entre los adultos autistas hay individuos cuyos signos se reducen a un carácter peculiar y a una tendencia a la reclusión, y también pacientes crónicos con diagnósticos tales como personalidad esquizoide, esquizofrenia simple, alteración obsesivo-compulsiva, perturbación afectiva, retraso mental, o daño cerebral.

De acuerdo a la cuarta edición del Diagnostic and statistical manual of mental disorders (DSM-IV), publicado por la Asociación Americana de Psiquiatría, el diagnóstico de autismo clásico en los niños implica la existencia de graves déficit cualitativos, tanto en su interacción social como en el lenguaje, la comunicación y el juego, además de otros déficit manifestados por estereotipias, perseveración y un espectro limitado de intereses y actividades. Otras formas menos comunes son los síndromes de Asperger, Heller y Rett. Al llegar a la edad adulta, alrededor de un tercio de los autistas sufren como mínimo dos episodios convulsivos epilépticos. Se ignora si existe alguna relación entre la epilepsia y la regresión exteriorizada del lenguaje, de la sociabilidad y del juego, aunque en $10 \%$ de esos niños se constata un perfil electroencefalográfico paroxístico, similar al observado en la afasia epiléptica adquirida. Es importante controlar la regresión en esta etapa, ya que sus síntomas pueden ser atenuados por la administración de medicamentos anticonvulsivos y esteroides.

El autismo, que se solía considerar una entidad poco frecuente, tiene actualmente una prevalencia estimada de $0,04 \%$ en la población en general. Puede atribuirse a varias causas biológicas, aunque ninguna guarda relación específica con él. Pese a su importancia, el componente genético no es exclusivo; el riesgo de recurrencia en familias con un niño afectado se estima en 3 a $8 \%$. Hasta ahora, ningún gen específico ha sido identificado en relación con el autismo, aunque se discute su posible vinculación con el gen responsable del transporte de serotonina.

Mucho se ha especulado acerca de las bases neurológicas del autismo, pero se carece de una teo- 
ría coherente, sea anatómica o fisiopatológica, para explicarlo, como también de una prueba biológica para diagnosticarlo. Aunque varias anormalidades han sido comprobadas por examen neuropatológico, análisis de imagen cerebral, electroencefalografía y caracterización de neurotransmisores y neuromoduladores, no se ha podido elaborar un concepto unificador que defina el autismo. En cuanto a su curso y pronóstico, ambos tienden a mejorar. En consecuencia, se aconseja estimular al niño en la etapa de regresión y estar alerta a una recaída en el transcurso de la adolescencia. El objetivo final es que el autista llegue a alguna comunicación con el entorno y de ese modo a cierto grado de independencia en su vida adulta.

Un diagnóstico correcto depende de una adecuada apreciación de los tipos de conducta propios del autismo y de una rigurosa evaluación del comportamiento social y del lenguaje, así como de la detección de actividades estereotipadas y repetitivas. Poca utilidad tienen las pruebas metabólicas, los estudios cromosómicos y los registros electroencefalográficos. Tampoco se dispone de fármacos o tratamientos curativos. Aunque muchos pacientes no requieren medicación, algunos psicotrópicos pueden ser útiles en ciertos casos: el metilfenidato mejora la capacidad de concentración y los antidepresivos inhibidores de la recaptación de serotonina controlan las estereotipias. En general, la intervención más eficaz es la educación temprana intensiva, dirigida a compensar las alteraciones de la conducta y de la comunicación. Además, los padres necesitan asesoramiento y apoyo y a menudo es preciso convencerlos de que no son responsables de la afección del niño. También necesitan información sobre las escuelas y grupos de ayuda a los que pueden recurrir. Es conveniente, asimismo, que los adolescentes y adultos autistas reciban un adiestramiento ocupacional que les permita desempeñar una actividad remunerada y prepararse para su futura convivencia en albergues apropiados, ya que la familia no puede protegerlos indefinidamente. Es importante propiciar las condiciones para que solo una minoría de autistas estén recluidos en instituciones psiquiátricas y para que todos tengan acceso a los beneficios del diagnóstico precoz y de una educación continuada. (Rapin I. Autism. N Engl J Med 1997; 337:97-104).

\section{Avances en el tamizaje de pacientes de cáncer}

Por primera vez se dispone de pruebas que confirman un descenso pequeño pero sostenido de las tasas de mortalidad por cáncer. Este descenso, observado en el período de 1990 a 1995, ha sido el resultado de medidas de prevención, diagnóstico temprano y tratamiento. En los niños, los beneficios del tratamiento son fácilmente cuantificables. En adultos, ya se ha documentado la contribución de la prueba de Papanicolaou a la reducción de la incidencia de cáncer cervical; la de la mamografía al diagnóstico oportuno del cáncer de mama, y la de la prueba de sangre oculta en heces a la detección de pólipos premalignos y de carcinomas intestinales en estadio temprano. En cambio, la radiografía de tórax y la citología de esputo no se han mostrado efectivas para el tamizaje de pacientes con cáncer de pulmón. La lucha contra el tabaquismo ha tenido algún éxito entre varones adultos, pero su influencia sobre las mujeres y los adolescentes de ambos sexos no ha sido tan notable.

En relación con el tamizaje de dos tipos de cáncer cuya incidencia ha aumentado en los últimos años -el cáncer de próstata y el melanoma maligno-, un editorial firmado por Chabner, Haluska y Talcott examina cuatro artículos sobre estos temas publicados en el mismo número de la revista. Tres de ellos se refieren al cáncer de próstata y a su diagnóstico por detección del antígeno específico de próstata (PSA), cuyas concentraciones en sangre están aumentadas en $90 \%$ de los hombres con cánceres prostáticos de $1 \mathrm{~cm}$ de diámetro o más. De estos tumores, solo $30 \%$ son palpables por examen digital del recto. Dado que pocos tumores detectados por determinación del PSA producen síntomas, corresponde evaluar si los costos del diagnóstico y tratamiento, así como los efectos adversos de este último en el largo plazo, se ven compensados por un beneficio ostensible para el paciente.

Concluyen Carter, et al., autores de los tres artículos citados, que la mayoría de los tumores asociados con concentraciones séricas de PSA entre 4 y $5 \mathrm{ng} / \mathrm{mL}$ requieren tratamiento, en tanto que una concentración inicial de $2 \mathrm{ng} / \mathrm{mL}$ solamente impone la repetición de la prueba a los 2 años. En cambio, Catalona, et al. intentan mejorar la sensibilidad de la prueba mediante la determinación de la razón de PSA libre a PSA total, ya que esta sirve para identificar a pacientes en alto riesgo aun dentro del grupo con concentraciones menores de $4 \mathrm{ng} / \mathrm{mL}$. Partin, et al. describen, por otra parte, un conjunto de parámetros para predecir la extensión de la enfermedad y su curabilidad: la presencia simultánea de una biopsia con lectura de Gleason de bajo grado, una concentración de PSA menor de $10 \mathrm{ng} / \mathrm{mL}$ y un tumor no palpable equivale a una probabilidad de $60 \%$ de que la enfermedad esté confinada a la próstata y sea, por tanto, curable por cirugía o radiación. En cambio, la combinación de concentraciones de PSA superiores a $20 \mathrm{ng} / \mathrm{mL}$, tumor palpable y lectura de Gleason compatible con diferenciación celular escasa a moderada indicaría una probabilidad de curación menor de 10\%. 
El aumento de la incidencia de melanoma cutáneo —en Estados Unidos de América se diagnosticaron 40000 casos en 1996- no se debe a una mayor detección de casos, sino a un incremento verdadero, probablemente consecuencia de una mayor exposición al sol. Si bien la detección temprana de nevos displásicos reviste urgencia, ya que la curación está directamente relacionada con la extensión y profundidad de la lesión maligna, no es fácil hacer el diagnóstico clínico, ni siquiera para los expertos, según aseveran Tucker, et al. Ya que en alrededor de $10 \%$ de los pacientes se constata una predisposición heredada a desarrollar nevos displásicos y melanomas, se anticipa que el análisis genético podría ser útil para identificar a pacientes en alto riesgo en quienes correspondería efectuar controles periódicos.

El editorial aquí resumido presenta numerosos avances en la lucha contra el cáncer, desde las investigaciones genéticas en curso hasta varias medidas ya adoptadas para prevenir, diagnosticar y tratar la enfermedad. Todos estos avances despiertan la esperanza de que en un futuro cercano se llegue a controlar el cáncer. (Chabner BA, Haluska FG, Talcott JA. Screening strategies for cancer: implications and results. JAMA 1997; 277:1475-1476).

\section{La salud del niño en edad escolar}

Actualmente el número de niños en edad escolar y la proporción que asiste a la escuela son mayores que en ningún otro momento en la larga historia de la humanidad. Este fenómeno, que refleja tanto el éxito de los programas dirigidos a mejorar la supervivencia infantil como el de las políticas de educación obligatoria, ha creado un nuevo desafío: asegurar la buena salud del escolar y simultáneamente un aprendizaje sin interrupciones por enfermedad. A fin de alcanzar estos objetivos, se ha propuesto el uso de los maestros, ya que en muchos países en desarrollo su número supera al de los trabajadores de la salud. Los resultados de análisis teóricos del Banco Mundial, según los cuales los sistemas de salud con componentes de edu- cación escolar podrían ser efectivos, llevaron a la formación de un consorcio de gobiernos, donantes y agencias técnicas (denominado The Partnership for Child Development) encargado de evaluar las intervenciones de salud, con sus respectivos costos, que se podrían emprender en el contexto de la educación primaria.

Como primer paso cabe definir el grupo en edad escolar, ya que en distintos lugares este difiere en sus características. Si tomamos el ejemplo de algunos países africanos, donde la vida escolar se inicia en la adolescencia, los mensajes de salud transmitidos en sus escuelas obviamente deben incluir la infección por virus de la inmunodeficiencia humana, el abuso de drogas, la planificación familiar y la violencia. En general, todo programa escolar de educación en salud debe adaptarse a la localidad en que se ha de aplicar, dada la gran heterogeneidad de edad y sexo que manifiesta la población escolar en distintas partes del mundo.

Hay una tendencia a creer que esa época de la vida es predominantemente sana, puesto que su tasa de mortalidad es más baja que en otras edades, pero este concepto debe revisarse en función de la tasa de morbilidad. Se ha comprobado, por ejemplo, un menor rendimiento escolar en niños con malaria, desnutrición, deficiencias de yodo y de hierro, y helmintiasis. Resulta evidente que toda inversión gubernamental tendiente a mejorar la salud de la población escolar y, por ende, su capacidad de aprendizaje, debe acompañarse de programas que aseguren la continuidad de los logros iniciales. Hasta ahora, los resultados de las investigaciones emprendidas por el grupo The Partnership for Child Development apuntan a la necesidad de mantener programas para mejorar la salud del niño en edad escolar y demuestran que el sector de la educación representa un medio práctico para alcanzar esta meta. Aún falta definir las estrategias que deben adoptarse, pero en principio deben abarcar componentes de educación sanitaria , servicios de salud y nutrición, instalaciones escolares adecuadas y políticas tendientes a proteger los derechos de los niños. (The Partnership for Child Development. Better health, nutrition and education for the school-aged child. Trans $R$ Soc Trop Med Hyg 1997;97:1-2). 